\title{
research
}

\section{A gift exchange relationship? Reflections on doing qualitative research with vulnerable migrants}

\author{
Roda Madziva, School of Sociology and Social Policy, \\ University of Nottingham, UK \\ Roda.Madziva@nottingham.ac.uk
}

Recent reflections on the study of forced migration stress the importance of constructing ethically sound research relationships that both respect research participants as autonomous agents and protect them from all forms of harm in the research process. Although this is important, very little research in this area has focused directly on the production of intimacy in the research process and how intimate research relationships that are produced can subsequently become the basis on which disclosures are shared and how this can contribute to both the quality of the research process and output. In this article I reflect on my intimate research relationship with Zimbabwean migrant parents who I interviewed in the United Kingdom. I argue that there is an element of (gift) exchange to intimate qualitative research encounters that yields benefits to both the researcher and the researched. In so doing, I also highlight some of the ethical dilemmas I encountered and how they were overcome.

key words gift exchange $\cdot$ migrant parents $\cdot$ Zimbabwean $\cdot$ children $\cdot$ relationship

\section{Introduction}

Recent reflections on the study of forced migration stress the importance of ethics and urge researchers to negotiate and construct ethically sound research relationships that not only respect research participants as autonomous agents but also protect them from all forms of harm during the research process (Hynes, 2003; Jacobsen and Landau, 2003; Mackenzie et al, 2007; Hugman et al, 2011). The main scrutiny in this area relates to the boundaries between the researcher(s) and the researched, how these shape power relations and often constrain the practical negotiation of ethical problems, often leading to the possibility of harming research participants - harm that extends beyond the physical to include emotional distress or the potential for re-victimising research participants by having them recount their painful stories. Although this is important, very little research in this area has focused directly on the 'production of intimacy in the labour of research' (Fraser and Puwar, 2008: 2) and how intimate research relationships produced can subsequently become the basis on which disclosures are shared and how this can contribute to both the quality of the research process and output. As Miller (2004: 218) argues: 
$[\mathrm{W}]$ ith regards to refugees, it is in fact the exceptional article that includes any discussion of the research relationship ... little if any mention is made of how the researchers were able to enter the refugee communities ... to what extent they were able to develop the sort of trusting relations that might have inclined the participants ... to provide truthful, accurate data.

Also, Bilger and Van Liempt (2010: 2) with regard to researching refugees write: 'we rarely get information on the research processes such as ... to what degrees participants were involved in the research.... Even less insight is provided in regard to difficulties experienced'.

This article attempts to fill this gap in knowledge through an exploration of the details of my research relationship with Zimbabwean asylum seekers who were living in the United Kingdom (UK) while forcibly separated from their children by immigration law. In so doing, the article highlights some of the ethical dilemmas researchers face when they are looking at hidden and vulnerable groups whose suffering is ongoing; when, in fact, the whole point of the research is to document that ongoing suffering in order to reveal the consequences of policy, and to press for political and policy change. The article argues that there is an element of (gift) exchange to intimate qualitative research encounters that yields benefits both to the researcher and the research participants.

The article starts by briefly discussing Mauss' (1935 [1954]) 'gift exchange' thesis to provide the theoretical context. This is followed by a discussion of the study and my own experience of leaving children behind the first time I moved to the UK, which positions me as an insider-researcher. I show how this personal experience facilitated the processes of reaching out to, and developing rapport with, my research participants. From there I go on to discuss the research process, a discussion that I limit to exploring the intersecting issues of access, trust building, power relations and the complexities of informed consent.

\section{Mauss' gift exchange theory}

Mauss' (1935 [1954]) gift exchange theory impresses on us the importance of giftgiving in the creation and maintenance of social relationships. Mauss argues that although processes of exchanging gifts are framed as voluntary in theory, they entail obligation in practice. Drawing examples from what he calls primitive or archaic types of society, famously Mauss notes that gift exchange relations compel individuals to fulfil threefold obligations of giving, receiving and reciprocating, and it is by satisfying these obligations that social relations are created, strengthened and maintained. In Mauss' view, the obligation to reciprocate arises from the powerful relations between giver and receiver such that after receiving the gift, the receiver often finds it almost impossible to enjoy the benefit of the gift without making a return to the giver. On the other hand, Mauss' analysis reveals that gift exchange is not without problems. Thus, he points at the ambiguity of gift exchange relations, showing how reciprocity inherently creates inequality while in effect inequality is also an endemic aspect of reciprocity. Nonetheless, to Mauss, the inequalities that occur in the context of gift exchange relations are far less detrimental when compared with relations of alienation and marginalisation that are predominantly significant in capitalist societies. 
In this article, I show how my own research relationship with Zimbabwean migrant parents resembles some elements of gift exchange and how Mauss' gift exchange ideas might have some relevance for contemporary qualitative research relationships.

\section{The research study}

This article is based on a study entitled “"A living death": Zimbabwean migrants in the UK who are forced apart from their children', which involved repeated interviews with 19 Zimbabwean asylum seekers (five fathers and 14 mothers) in the UK who had been forced apart from their children by immigration law for a lengthy period of time of between five and 10 years. The study was conducted between October 2008 and January 2010. By conducting this research, I aimed to gain an in-depth understanding of these parents' lived experiences of being separated from their children as well as to understand the human rights violations they suffered, both as citizens (in Zimbabwe) and as asylum seekers (when they moved to the UK). I also sought to gain an understanding of how their new identities in the UK further complicated their own lives and those of the children left behind.

Meanwhile, reflexive accounts of studying the social world of which one is a part of and/or of undertaking research that reflects one's own personal experience have received significant recognition in contemporary social science research, especially health-related studies (see, for example, Watts, 2008). In studying the experience of Zimbabwean migrant parents who are separated from their children, I was not merely exploring a topic in which I was interested as a researcher, but also a situation that I myself experienced. In 2006, I happened to be one of the very few Zimbabwean women given the opportunity to migrate to the UK for study purposes. Although my plans were initially to migrate together with my husband and two children, things did not go according to plan as I encountered problems in securing a UK visa. Although eventually I was successful, it took so long for the decision to be made that by the time the visa issue was resolved, circumstances forced me to leave my husband and two children in Zimbabwe. The plan was therefore that I would migrate to the UK first, and afterwards make arrangements for my family to join me. However, when I arrived in the UK, again things did not turn out as I had hoped - plans for being reunited with my family were frustrated, resulting in us being forced apart for over one year.

This period of separation was made especially painful and difficult by the fact that I was not in a position to explain to my children why we could not be together despite my promise that they would join me in the UK within a very short time. Although I made it a point to call my family regularly, what troubled me most was the fact that every time I called, my daughter would say to me: 'Mum I miss you badly; when are we coming over to be with you?' Frequently, I stumbled at these words, as I was not in a position to give her a definite answer. Usually, I would end the conversation by assuring her that they would join me very soon. We got to a point where one day, my daughter said to me: 'Mum can you please give me the exact date we are coming over? You have been saying to me very soon, and it seems very soon will never come. Please don't fail me mum..., otherwise I will never trust you again.'These words really pierced my heart as I strongly believe that the worst thing for any mother would be for her children to lose their trust in her. Yet, in my case, as much as I did not want this to happen, I was powerless to give her the definite answer she wanted. I also felt 
powerless more generally not only in relation to my children's lives, but also in terms of making others around me understand what I was going through.

Eventually, I was reunited with my family, but this personal experience not only sparked my research interest in the phenomenon of migrant parents' separation from their children, but also helped me to gain access to research participants, win their trust and generate rich research data that reflect the in-depth accounts of their painful experiences of separation. In this article, I will constantly reflect on how my personal experience came to play a significant and beneficial role throughout my research journey. In the discussions that follow, I will attempt to engage the reader with the actual research process, highlighting the ethical dilemmas that arose and how they were overcome.

\section{Negotiating access}

The difficulties of gaining access to forced migrants, especially those who do not reside within refugee camps and detention centres and those with precarious immigration status, have already been widely documented (Hynes, 2003; Jacobsen and Landau, 2003; Lammers, 2007; Schmidt, 2007; Empez, 2010). Besides being among the most 'hard-to-reach' categories of socially excluded people (Hunt, 2008; Bilger and Van Liempt, 2010), some (eg, Hynes, 2003) observe that forced migrants are also people whose lives have been fashioned by complex traumatic experiences and as a result, they can no longer trust others, including members of their own communities.

In my own research, I experienced difficulties with regards to gaining access to my research population. Due to the absence of statistics on the number of Zimbabweans in the UK or those who are in the UK without their children, purposive sampling was considered the ideal technique, and I resolved not to concentrate on any specific region but rather to secure interviewees from any region possible. Initially, I aimed to gain access to this population through informal networks. As a starting point, a Zimbabwean female friend introduced me to her friend who was a refused asylum seeker, who in turn made considerable efforts to link me with friends and relatives whose situations matched my research interests. Despite all her efforts, I faced resistance from most of the potential respondents and from what I later gathered the main problem was that of mistrust. In his study with Burmese refugees in the UK, Hynes (2003) notes that mistrust among forced migrants can be a result of many factors, most of which are directly embedded in the forced migrants' experiences of both pre- and post-migration. Such insights are very useful as they help to explain some of the reasons why I was mistrusted by my fellow Zimbabweans in a foreign land.

First, most of the Zimbabwean refugees in the UK are people who have suffered human rights violations in Zimbabwe in the context of the country's political violence, which saw many citizens being targeted as enemies of the Mugabe regime due either to their political affiliation or to their ethnic background. This background, it seems, had an influence on the potential respondents' perceptions of me. Although I approached individuals as a researcher, people routinely expressed anxiety to know who exactly I was, my tribe and most critically my political affiliation. Their greatest fear was that I was one of Mugabe's central intelligence officers (CIOs). Interviewees subsequently told me: "It is now common knowledge that quite a number of Mugabe's CIOs have been granted asylum here. It is now confusing, we cannot tell who exactly is a genuine researcher." Second, migrants wanted to know more about my own social 
networks in the UK as I never used to attend Zimbabwean social events and also I did not belong to any Zimbabwean community networks. Perhaps, due to the stigma attached to both asylum seeking and leaving children behind, individuals wanted assurance that sharing their intimate life stories with me would not have any negative social bearing on them (see Markova, 2010). Third, perhaps due to rumours that the Home Office increasingly engages researchers in their hunt for illegal migrants (Pasura, 2006), potential respondents suspected that I could be masquerading as a researcher while working as a Home Office watchdog. Thus, as pointed out by Hynes (2003: 5), there is 'a boundless universe of mistrust' that can arise when trying to gain access to research forced migrants.

To overcome some of these problems I tried to avoid 'overdependence' on social networks and had to consider the use of 'multiple networking approaches' (Bloch, 2007). I knew of a Zimbabwean community network in the Midlands and decided to start attending their meetings, which eventually gave me the opportunity to post the details of my research on the network's website, which generated considerable interest. Perhaps due to the fact that I was operating under the auspices of a trusted organisation, I faced less resistance from potential respondents. However, gaining access to their intimate experiences and emotions nonetheless involved going through the process of trust building, described below, with each individual.

I also heard of an African women's organisation in the Midlands founded and run by African women who are asylum seekers and refugees and later discovered that its founder was actually a Zimbabwean woman. Initially, I faced resistance from the leader of the organisation. This echoes Bogdan and Taylor's (1998) and Keval's (2009) insights that those who hold the position of the 'gatekeeper' often exercise protective power in authorising or denying access to vulnerable populations. However, I kept on trying for almost six months, in line with Cassel's advice on negotiating 'closed access': '[A]mong the characteristics needed to penetrate a closed access group are brute persistence and blind compulsivity. One has to keep on pushing, and trying, and hoping, and smiling, and pushing some more. For this, a researcher needs a thick skin and a certain imperviousness to rejection' (Cassel, 1988, as cited by Arber, 1993: 54).

In my case, access was eventually gained through a friend who personally knew the woman in charge of the group. It eventually turned out that the group leader was herself a refused asylum seeker who had been separated from her children for almost eight years.According to Arber (1993), having penetrated a closed access, the researcher needs to be highly socially sensitive to the culture and practices of the group. Such insights offer useful parallels for thinking about the level of my social engagement with prospective participants at the African women's group where being sensitive to the asylum women's situations was virtually mandatory and almost certainly crucial to winning their trust. I recall that on my first visit to the organisation, I found the group members busy painting and the situation compelled me to join in, in order to identify with them. For the next six months that I frequented this place, I took part in many of the group's activities, including a fundraising programme, seminars, helping to put their office in shape and assisting with administration work. This commitment helped to dispel some threads of mistrust although I still needed to go through the process of trust building with individuals in order to gain access to their private lived experiences.

Reflecting on his research with refugees from Afghanistan, Bosnia and Guatemala, Miller (2004) makes a clear distinction between physical and interpersonal access, 
arguing that after gaining physical access the researcher will still need to undergo another essential process - the process of negotiating interpersonal access in order to develop mutual and trusting relationships with refugees, especially those who 'have developed a self-protective insularity in response to their experiences of marginalization and oppression' (Miller, 2004: 217).

Such views are of critical relevance to my own research. Although I approached and respected my research participants as autonomous agents in the sense of their being conscious, living and purposive actors, the asylum and immigration system had 'oppressed' and in effect stripped them of the ability to assert their will; not only with regards to pursuing their life-project of bringing their children over to join them in safety, but also even the capacity of continuing to support them financially back home. Thus, it becomes apparent that when asking people to talk about experiences or a situation in which they feel vulnerable, marginalised, exploited, harmed or excluded, it is almost always difficult because they often find it dishonouring, and difficult more generally to admit that they are powerless or simply have been a victim without losing face.

Furthermore, my participants feared that others perceived them as autonomous agents who could or should have made different choices, making it almost impossible for them to share their pain even with members of their own community. Thus, in order to draw these parents into a meaningful research dialogue that would allow me to gain access to the private and intimate details of their lives in a humane and non-deceptive way, I needed to first develop trusting relationships with them.

\section{Developing trust}

As argued by Miller (2004: 218), trust building is a prerequisite to developing meaningful research relationships in qualitative research especially when researching sensitive topics, yet in the existing literature, questions about trust either as a methodological or ethical issue continue to be given less priority where discussions about the researcher-researched relationship are raised. As a result, there is less acknowledgement that research participants increasingly 'shape their responses based on the relative degree of trust they feel towards the researcher' (Miller, 2004: 219). For Dickson-Swift et al (2007), establishing trustworthy research dialogues with research participants involves an exchange process despite the fact that researcher and participant do not normally negotiate a formal contract about what will be exchanged. This echoes the Maussian view on the importance of trust in gift societies where processes of exchange are profoundly embedded in trusting social relations. However, in a sensitive research context, building trust demands a lot of effort and patience.

So, for example, in my research, my initial step towards building trust with participants involved investing time and energy in maintaining close contacts with potential respondents who had been referred to me, but on a more social basis. This involved establishing rapport by engaging individuals in more general discussions, which often gave me the platform to openly disassociate myself from both the Mugabe regime and the UK Border Agency, while at the same time allowing participants to know more about me. This involved giving individuals time and space to ask any questions they had, be they directly about me as a person or the proposed research. Miller (2004) used a similar approach in his research with Guatemalan refugees; often 
he found himself in a situation where he had to consistently make his opposition to the Guatemalan government more explicit in order to win participants' trust.

Also, in my research, dialogue was developed through exchanging with participants the general experiences of living through adversity during the time we were in Zimbabwe, sharing how we coped with life, especially in relation to the economic and political hardships that characterised the country from the mid-1990s. Some of the popular discussions also related to issues around diasporic identities and cleavages, including the difficulties of living in a foreign land, especially the extent to which people experienced racism and discrimination. Scott (1999) also found some of these topics helpful for 'bonding' and building rapport when she carried out research with her Caribbean counterparts in the UK. Where the situation allowed, I would increasingly discuss my own experiences of leaving children behind in order to further bond with research participants on the basis of shared experience. So, for example, in one situation I shared my sad story of separation with my children, describing how I found it hard to explain especially to my daughter why we were separated, which subsequently prompted the 45-year-old male potential participant I was conversing with to disclose that: "I now dread phoning home - calling home has long ceased to be a joy ... I don't have anything to tell my children about why they cannot come to join me here...." Indeed, by the time this participant consented to take part in my research we had already bonded on the basis of shared experience.

The process of establishing trust also demanded that I demonstrate to potential participants that I was genuine and trustworthy. Among other things, this called for me to engage in a process of exchanging personal information such as home and mobile telephone numbers and opening up my life by encouraging people to call whenever they felt they wanted to talk to me (see Markova, 2010). With time, this approach yielded results, as potential respondents increasingly took the initiative to call or text, asking if I was available for a chat. In one situation, a female potential respondent called me and openly acknowledged that she found it very useful to talk to someone from home in a non-judgemental manner. We then agreed to meet for the first time and by the time we met for the actual interview we were already familiar to each other, which helped to facilitate the interview process.

It is also important to underscore that the need to establish trusting relationships with research participants significantly impacted on the choice of methods. As discussed earlier, my research participants were individuals who had suffered many traumatic experiences in different contexts (as citizens in Zimbabwe and later as asylum seekers in the UK), and hence seemed not to trust anyone. Given this situation, a conventional one-off interview would have been a 'hit and run' exercise and a method unlikely to allow me to penetrate the depth of their lived experiences (also see Rosenthal, 2003). Thus, repeated interviewing seemed the only technique that would afford them enough time both to reflect on some of their experiences and to decide on the ones they felt comfortable about discussing with a researcher. Therefore, I decided that, instead of conducting one-off and necessarily superficial interviews with a large number of members of this hard-to-reach population, trying to quickly solicit information 'to leave, never to return', I would instead settle on a small sample and conduct repeat interviews 'more intimately' with a small number of respondents in order to gain an in-depth understanding of their experiences (see Wax and Shapiro, 1956: 215-16). 
Repeated interviews were also necessary because of the particular problems presented by working with migrant parents separated from their children. Most of the interviews I conducted in the first round were extremely emotionally charged such that I found some of them very difficult to moderate. In her work with traumatised groups, including survivors of the Shoah and other groups of asylum seekers in Germany, Rosenthal (2003: 918) makes the important observation that initial interviews with traumatised individuals should be treated mainly as moments of respectfully listening and affirming their stories - there is no room for questioning:

This so-called main narration is at no time interrupted by questions from the interviewers, but instead, it will only be supported by paralinguistic expressions of interest and attentiveness such as 'mhm' or during narrative interruptions through motivating incitements to continue narrating .... this phase of the conversation is of great advantage for traumatized people when we later try to initiate further narrations.

In my research, repeat interviewing became an important technique in that the subsequent rounds of interviews were mainly designed to follow up on issues and themes that were touched upon in the main interview and also to get an update on some of the ongoing issues. Indeed, most respondents seemed more settled and at ease during follow-up interviews, and could therefore clarify issues as well as discuss ongoing experiences in a calmer way than they could do initially. Thus, through multi-interactions, intimate relationships were developed and nurtured to a level where respondents came to trust me as their confidant and could discuss intimate experiences openly, which in turn also enabled me to approach personal matters in a friendly but straightforward manner.

\section{Power relations}

While developing intimate relationships with participants is critical, especially in the sense that they subsequently allow the researcher easy access to participants' intimate life experiences, some scholars (eg, Fanow and Cook, 1991; Nast, 1994) have observed that when power relations between researcher and researched are highly unequal, the potential for ethical problems to arise is significantly high. Non-hierarchical relationships in research are therefore considered ethically desirable because they help to address such problems. However, Scott (1999) argues that it is possible for a researcher to assume multiple identities, and this on its own may help to settle the difficulties that arise in the context of unequal power relations. Using the example of her own research with her Caribbean counterparts, Scott (1999: 90) suggests that shared aspects of identity (in her case gender and race) can allow researcher and researched to transcend other aspects of social difference (eg, class) and attain a higher level of trust and intimacy. I find some useful parallels here for thinking about the level of trust I eventually gained with my participants, and yet it strikes me that rather than resolving ethical issues, the creation of intimate social bonds between researcher and researched opens up new dilemmas. Once these intimate bonds were established, did my interviewees feel under an obligation to almost 'give everything'?

After going through the processes described above to establish trust, there was a strong sense of familiarity between me and my interviewees, derived from us being 
'black' Zimbabweans who had gone through similar painful experiences in a foreign land, a bond that was reinforced through conversing in our native languages and through other cultural gestures like the shaking of hands.

In a research study that investigated the challenges that are often faced by qualitative researchers, Dickson-Swift et al (2007: 332) employed the phrase 'researcher's selfdisclosure' to describe the researcher's involvement in a reciprocal sharing of personal experiences (also see Duncombe and Jessop, 2002; Liamputtong, 2007).These authors further showed that by putting oneself on a 'level playing field' (Dickson-Swift et al, 2007) with participants, the researcher's power is slightly neutralised to a level where relationships can become non-hierarchical. These observations have some bearing to my own research where it became explicitly clear that sharing my own experience of leaving children behind the first time I moved to the UK increasingly placed me on a 'level playing field' with my participants. Indeed, the courage to share my own personal experience with participants positioned me as a member of the inner-circle - somebody who was empathetic, non-judgemental, understanding and supportive. Also, the idea that I could immediately understand when interviewees recalled past events or tragedies that took place in Zimbabwe further strengthened the sense of a shared history and social bond (see Scott, 1999; Markova, 2010).

Therefore, research relationships that are anchored on social bonds and reciprocity of disclosure can not only contribute to the generation of authentic in-depth data, but can also allow for disclosures to be made in an atmosphere of safety (Corbin and Morse, 2003; Dickson-Swift et al, 2007; Watts, 2008). The merits of bonding with participants were fully borne out in my research where participants came to trust me to the point of willingly sharing the depth of their life experiences, which, I believe, would not have been the case had they been interviewed by a British researcher (see Markova, 2010).

Trust built on a shared identity is a double-edged sword for the researcher, however. As Young (2004) notes, being taken as an 'insider' can hamper the interview process as respondents tend to assume that the researcher is aware of certain things, especially events, experiences and attitudes embedded in their shared social, political and cultural context. I too experienced this problem, as interviewees routinely provided answers like "being a Zimbabwean woman, you should know what I mean by this". I tried to overcome this problem by telling respondents that although I was aware of certain issues as a Zimbabwean woman, as a researcher I needed them to explain events and experiences in detail and make explicit their attitudes for the benefit of my audience, mostly British academics who - I would tell respondents - knew absolutely nothing about Zimbabwe or their problems. This strategy worked well, encouraging respondents to expand and clarify without taking offence.

In the context of my research, it is also important to consider the specificity of my interviewees' experience. Techniques for establishing trust and rapport with research subjects, and questions about power relations and the ethics of research, cannot be detached from the particularities of the research. So, for example, in the case of my interviewees, I was asking migrants for retrospective accounts of what made them decide to leave Zimbabwe, what arrangements they had made for their children before leaving and their experiences of arrival and of leading a life in limbo. The accounts they offered me were undoubtedly shaped by the guilt and shame they felt as they reflected back on how things were at the moment they decided to leave, their knowledge of how things had changed for the worse for their children since they 
left, and the contrast between what they had hoped their lives would become and what their lives had turned out to be in the UK. Thus, despite my being intimately connected to research participants, I was interviewing individuals for whom suffering had become part of their identity. In his work with Liberian refugees in Sierra Leone, Jefferson (2010: 23) writes:

Were we to say suffering is accumulated we would stray close to implying that it is amassed, collected over time, as if a series of discrete events combined and contributed to the current experience of suffering. True enough discrete events have featured in the lives of the refugees, but to the degree that they have been lived through and lived with they contribute not to a set of experiences of sufferings added one on top of the other but to a contemporary experience of suffering which is no less than an experience of self as sufferer... Suffering is not a form of life, a choice amongst many. Suffering for them is life.

Similarly, for my interviewees, suffering had become life, and in this sense, I was different from them. Thus, in relation to their marginalised position in the UK, especially their lack of certain rights, including the rights to work and family life, I was perceived to be a privileged 'Zimbabwean woman' - I had succeeded in bringing my family over to the UK as well as being successful more generally in terms of fulfilling my academic plans.

In the context of some research, the relative privilege of the researcher can be a potential source of unequal power relations (see Fanow and Cook, 1991; Miller and Glassner, 1998).Yet, in my case, my privilege meant something slightly different from my respondents who took me as a 'sister' and 'daughter'. They made it clear that they hoped and believed that speaking to me of their suffering was a way in which to have their identity, their humanity and personhood, recognised, validated and affirmed. Indeed, it has already been acknowledged in literature that participation in sensitive research often provides an opportunity for participants to talk and to be listened to by a person who is genuinely interested in their experience and who really values them as a human being (Corbin and Morse, 2003). I can argue that my respondents 'gave themselves' to me in anticipation that I would in turn give them a voice in a foreign land; something that actively required me to be in a more privileged position than their own. In essence, respondents regarded me as their 'hero' or advocate as one 45-year-old woman participant put it: "We feel privileged and honoured to be able to identify with someone who has already conquered the war we are in....You need to let the British government know that we are not statistics as they take us to be ... but we are really people with flesh and blood...." In ethical terms, this represented another double-edged sword. On the one hand, it could be argued that the 'power' that resides in the 'traditional interviewer' was neutralised (Scott, 1999: 90) - I was not an authority figure using them as objects for data collection, I was a vehicle they believed they could use to get their stories of suffering to the outside world. But on the other hand, as much as I was committed to the role they wanted me to play, I was also a researcher gathering data for my own academic purposes and advancement, and drawing them into an intimate research relationship in order to fulfil those goals. 


\section{Informed consent}

The need to obtain informed consent from research participants was considered paramount during fieldwork. Indeed, respondents who had agreed to participate in my study were presented with a consent form, in line with traditional ethical guidelines on obtaining consent from research participants (Corbin and Morse, 2003). And yet due to reasons associated with unstable immigration status, almost all my respondents stated that they preferred to give only verbal consent and did not wish to commit themselves in writing. As my research involved multiple interactions with these participants, a conventional one-off consent form would have been inadequate in any case. It was important for me to continually remind respondents that they were not under any compulsion to participate and that they were free to withdraw from the study at any stage without having to give any reasons. In principle, I can argue that all my interviewees fully consented to take part in the research and that none of them chose to withdraw their participation at any stage of the research process. At the same time, on making this claim, I am also aware of studies (eg, Mackenzie et al, 2007; O'Connell Davidson, 2008; Stevenson, 2009), which argue that there are other ethical concerns that can emerge once a researcher and research subject engage into a longer-term, intimate research relationship. As O'Connell Davidson (2008: 51) put it: '[I]f someone does give informed consent to a lengthy period of participation in research that closely interrogates ... the intimate details of her life, experience and emotions, should we accept that "Yes" means "Yes"?'. So far as my research is concerned, questioning whether 'yes' means 'yes' is an issue that raises the following ethical questions:

- Do people who need to be 'given a voice' because they are suffering, disenfranchised and hence powerless have the power to consent?

- Are victims in control of their decisions and actions? Can they exercise agency?

Reflecting on these questions leads me to conclude that, for my respondents, consent to participate in research linked both to their sense of powerlessness and to their wish, as agents, to challenge and transform that powerlessness. They actively wanted their experiences to be known to somebody they perceived as having the power to somehow let the world know about their suffering and the injustices that caused it.

As one participant in Dickson-Swift et al's (2007: 330) study correctly put it, informed consent is:

so much more than just signing a form to say that they are willing to offer you information, they are actually allowing you into their lives, they are telling you personal information that might be quite hard, so you need to demonstrate a certain degree ... of appreciation for what they are doing 'cause the reality is that it is more than just words ... it's their life, their experience....

Through my research, I was repeatedly witness to scenarios and expressions of marginality, vulnerability, suffering, helplessness, powerlessness, victimhood, guilt and shame, which characterised my participants' narratives at different levels and throughout the research process. The concept of 'emotional work' (James, 1989; Li and Arber, 2006), which frequently is used to explain how certain professionals get 
involved in managing other people's emotions, seems relevant to understanding how researchers manage participants' emotions. I recall that interview discussions, particularly with women respondents, frequently led to the shedding of tears, with some sobbing uncontrollably, especially when discussing for the first time issues surrounding the abuse and exploitation that their children were suffering back in Zimbabwe. Although in these circumstances, I always asked my respondents if they wanted to stop the interview completely or if they wanted to change the topic of discussion, in all cases respondents expressed the desire to continue narrating their painful experiences, driven, I believe, by the desire to be heard. This echoes Corbin and Morse's (2003: 342) views that:

an interview is an exchange. The participants sometime share intimate information, but the researcher gives something in return: a sense of presence or of being with the participant in the story.... Usually there is no overt or spoken contract between participant and researcher about what the exchange will be....

It was the verbal and non-verbal responses and affirmations given to participants at the different stages of the interview that allowed their stories to unfold. For example, in one situation, a 37-year-old woman whose child died in Zimbabwe while she was trying to have her asylum settled in the UK, emotionally told her story that provoked feelings of deep loss, grief and despair. After she had calmed down, she said she had waited for this opportunity for a very long time. "At last God has answered my prayer....", she said, suggesting that she had finally managed to empty her heart to a person she believed had the capacity to make the pain and disenfranchised grief she had suffered for many years visible to and recognised by others. In another case, a 45-year-old female respondent, sobbing, bitterly insisted: "I want my experiences of seeking asylum in this country to be documented and my sufferings to be made known to the public ... I want it to be known that this is the cruelty we suffer in this country when we come here to be protected."

Given the emotionally charged research environment I have described above, it becomes apparent that carrying out this research was not an emotion-free process. Among other things, the most emotionally challenging aspect of the research was that of routinely listening to the interviewees' narratives of shame, powerlessness and hopelessness as they echoed and re-echoed their never-ending stories of separation from their children, which in some cases was permanent and final. Some have correctly argued that qualitative researchers are not simply 'spectators who are only documenting the narratives of others and reporting on them, but they are aware that the way in which they experience reality is captured through different lenses, whereby one of them is the emotions of the researcher him or herself' (Nutov and Hazzan, 2011: 21). Others have also correctly noted that rapport is mutually cultivated between individuals who can sympathise with each other. Corbin and Morse (2003:343) write:

[D]uring these intense and distressful moments, researchers often connect with participants at a very deep level. They too are caught up in the story and share feelings of loss, grief, and/or anger with participants. At the same time, experienced qualitative researchers are able to step back and provide 
the empathy and support that participants might need to work through troubling experiences.

I recall many cases in which comments like "thank you for giving your people a voice in a foreign land" were echoed by respondents following an interview, who at the same time seemed desperate to know about how soon the research would be disseminated to the public so that their suffering could be made open to the outside world.

As noted by Dickson-Swift et al (2007: 336): '[W] hen qualitative researchers interact with research participants on a personal level, there is a possibility that the boundaries between the researcher and research participant can be blurred ... and many find participation in research has enormous therapeutic value.' Indeed, for my participants, having someone listening to their painful stories and feeling for them sometimes transformed interview sessions into moments of confession, which, I believe, some found cathartic (Birch and Miller, 2000; Ortiz, 2001). As argued by Corbin and Morse (2003:338) interviewees' distress is often 'counterbalanced by the therapeutic effects of being able to talk to a non-judgemental person and perhaps even to gain some insight and closure on unresolved issues'. Because the interview allowed my participants to tell their story to another person who understood that they had not chosen to abandon their children, and that the decision to leave their children behind was unavoidable, it appeared to provide a sense of forgiveness and healing for respondents, or at the very least some relief from the endless guilt. Thus, respondents often expressed gratitude to me at the end of the interview, just as I expressed my gratitude to them.

\section{Discussion and conclusion}

Abstract discussions about research ethics and the overarching principles that ought to guide social researchers sometimes fail to address or even do injustice to the everyday research encounters and the nature of relationships they produce. This is especially so when research involves participants from marginalised or oppressed groups. Questions about how to conduct ethically sound research with human beings in general, and vulnerable groups such as forced migrants in particular, ought not to be entirely and procedurally isolated from questions about the everyday social norms of human interaction. Through my research, I managed to gather data for my own academic purposes and advancement, something that could only be achieved by drawing participants into an intimate relationship in the ways described above. But the participants in my research were not objects for data collection, they were human beings, and conducting the research required me to enter into a social and human relationship with them. In the context of that social relationship, my respondents gave me something extremely valuable and important, and the relationship could therefore be characterised as a form of gift exchange. As a researcher, I was committed to ensuring that participation in my research did no harm to participants, but as a human being involved in a social relationship, this was not enough. I wanted to do more than merely avoid harming the people who helped me.

As noted above, participants could be said to have benefited from the emotional catharsis that comes from speaking about pain and suffering - through telling their stories, participants achieved relief from the guilt and grief they had suffered silently often for many years. Another reciprocal benefit from participation in the research was 
the platform afforded to participants to reclaim their personhood, dignity and honour by helping another person. My respondents came to trust me, feel connected to me, and were eventually drawn into an intimate relationship within which it was possible for them to give me a gift (their private and intimate life experiences). This capacity to give to another person, to help someone they felt connected to, was important to them in the context of their utter powerlessness to influence their own situations in the UK and to assist and support their children back home. The research relationship was thus a gift exchange. Although Mauss (1935 [1954]) emphasises the obligation to reciprocate that which is given in either equal or greater value than that which was received, in my estimation, my participants were able to give me something more valuable and longlasting than what I was able to give to them. Thus, in this sense, it can be argued that thinking of research as a form of gift exchange places an ethical obligation on the researcher to reciprocate; yet, in the researcher capacity, such an ethical obligation is often almost impossible to honour fully (O'Connell Davidson, 2008).

Reflecting on my research with Zimbabwean migrants draws attention to temporal aspects of ethics that are rarely acknowledged in traditional discussions of research ethics. So, for example, time matters in relation to the obligations generated by research (see O'Connell Davidson, 2008). Although Mauss (1935 [1954]) notes that once established, a gift exchange relationship has to be maintained through ongoing mutual interactions, particularly owing to the fact that individuals constantly feel indebted to each other and that the obligation continues 'until the giver is restored to a state of wholeness' (Hanna, 2009: 12), in my case, it would have been impossible to restore my participants to a state of 'wholeness' or even to maintain intimate relationships with them indefinitely, despite strong feelings of 'indebtedness'. Although I am privileged relative to my research participants in the sense that my immigration status is (slightly) less precarious than theirs, and I am lucky enough to have my husband and children with me in the UK, I am not powerful in the sense of being able to transform the things that caused their suffering, nor am I in a position to devote myself full time to advocacy and political struggle on their behalf. I received a very special gift from my research participants, but I was not and am not in a position to maintain the process of giving, receiving and reciprocating beyond the time period of the research. For me, as for most researchers, the relationship with research participants was time limited. It may have been longer than in 'hit and run' research, but to place time limits on any relationship characterised by intimacy and obligation necessarily leaves a sense of ethical discomfort (see Watts, 2008). In my case, I hope that this can be assuaged partly by attempting to ensure that the research findings do impact on the policies and practices that combine to cause the vulnerability and suffering of migrants like my research participants.

\section{Acknowledgements}

I would like to thank Julia O'Connell-Davidson for her helpful suggestions and encouragement during the process of writing this paper. I also would like to acknowledge Naomi Tyrrell and the anonymous reviewers for their comments and engagement with the paper. 


\section{References}

Arber, S, 1993, The research process, in N Gilbert (ed) Researching social life, London: Sage Publications

Bilger, V,Van Liempt, I, 2010, Introduction: methodological and ethical concerns in research with vulnerable migrants, in IVan Liempt,V Bilger (eds) The ethics of migration research methodology: Dealing with vulnerable immigrants, Brighton: Sussex Academic Press

Birch, M, Miller, T, 2000, Inviting intimacy: the interview as therapeutic opportunity, International Journal of Social Research Methodology 3, 189-202

Bloch, A, 2007, Methodological challenges for national and multi-sited comparative survey research, Journal of Refugees Studies 20, 2, 230-47

Bogdan, R, Taylor, S, 1998, Introduction to qualitative research methods: The search for meanings (2nd edn) New York, NY: Wiley

Corbin,J, Morse JM, 2003, The unstructured interactive interview: issues of reciprocity and risks when dealing with sensitive topics, Qualitative Inquiry 9, 3, 335-354

Dickson-Swift,V,James, EL, Kippen, S, Liamputtong, P, 2007, Doing sensitive research: what challenges do qualitative researchers face?, Qualitative Research 7, 3, 327-53

Duncombe, J, Jessop, J, 2002, Doing rapport and the ethics of faking friendship, in M Mauthner, M Birch, J Jessop, T Miller (eds) Ethics in qualitative research, London: Sage Publications, 107-22

Empez, N, 2010, The fieldworker as social worker: dilemmas in research with Moroccan unaccompanied minors in Spain, in I Van Liempt, V Bilger (eds) The ethics of migration research methodology: Dealing with vulnerable immigrants, Brighton: Sussex Academic Press

Fanow, MM, Cook, JA, 1991, Beyond methodology: Feminist scholarship as lived research, Bloomington, IN: Indiana University Press

Fraser, M, Puwar, N, 2008, Introduction: intimacy in research, History of the Human Sciences 21, 4, 49-67

Hanna, A, 2009, Marcel Mauss' Essai sur Le Don (The Gift), PlatForum: Journal of Graduate Students in Anthropology, 10, 11-14

Hugman, R, Bartolomei, L, Pittaway, E, 2011, 'Human agency and the meaning of informed consent: reflections on research with refugees', Journal of Refugee Studies $24,4,655-71$

Hunt, L, 2008, Women asylum seekers and refugees: opportunities, constraints and the role of agency, Social Policy \& Society 7, 3, 281-92

Hynes, T, 2003, The issue of 'trust' or 'mistrust' in research with refugees: Choices caveats and considerations for researchers, New Issues in Refugee Research, Working Paper no 98, Geneva: Evaluation and Policy Analysis Unit, United Nations High Commissioner for Refugees

Jacobsen, K, Landau, LB, 2003, The dual imperative in refugee research: some methodological and ethical considerations in social science research on forced migration, Disasters 27, 3, 185-206

James, N, 1989, Emotional labour: skill and work in the social regulation of feelings, Sociological Review 37, 15-42

Jefferson, AM, 2010, Performances of victimhood, allegation and disavowal in Sierra Leone, Paper presented at the workshop: Human Rights,Victimhood and Consent at the Uni Rokkan Centre, Bergen in Norway, June 9th to 13th 2010

Keval, HC, 2009, Negotiating constructions of 'insider' / 'outsider' status and exploring the significance of dis/connections, ENQUIRE 4, 51-72 
Lammers, E, 2007, Researching Refugees: Preoccupations with Power and Questions of Giving, Refugees Survey Quarterly, 26,3, 72-81

Li, S, Arber, A, 2006, The Construction of Troubled and Credible Patients: A Study of Emotion Talk in Palliative Care Settings, Qualitative Health Research, 16,1, 27-46

Liamputtong, P, 2007, Researching the vulnerable, London: Sage Publications

Mackenzie, C, McDowell, CM, Pittaway, E, 2007, Beyond 'do no harm': the challenge of constructing ethical relationships in refugee research, Journal of Refugee Studies 20, 2, 299-319

Markova, E, 2010, The 'insider' position: ethical dilemmas and methodological concerns in researching undocumented migrants with the same ethnic background, in I Van Liempt, V Bilger (eds) The ethics of migration research methodology: Dealing with vulnerable immigrants, Brighton: Sussex Academic Press

Mauss, M, 1935, The gift, London: Cohen and West, 1954

Miller, J, Glassner, B, 1998, The 'inside' and 'outside': finding realities in interviews, in D Silverman (ed) Qualitative research: Theory, method and practice, London: Sage Publications

Miller, K, 2004, Beyond the frontstage: trust, access and the relational context in research with refugee communities, American Journal of Community Psychology 33, 3/4, 217-27

Nast, H, 1994, Opening remarks on women in the field, Professional Geographer 46, 1, 54-66

Nutov, L, Hazzan, O, 2011, Feeling the doctorate: is doctoral research that studies the emotional labour of doctoral students possible, International Journal of Doctoral Studies 6, 1-31

O'Connell Davidson, J, 2008, If no means no, does yes mean yes? Consenting to research intimacies, History of the Human Sciences 21, 4, 49-67

Ortiz, SM, 2001, How interviewing wives became therapy for wives of professional athletes: learning from a serendipitous experience, Qualitative Inquiry 7, 192-220

Pasura, DM, 2006, Mapping Exercise Zimbabwe, International Organisation for Migration (IOM).

Rosenthal, G, 2003, The healing effects of storytelling: on the conditions of curative storytelling in the context of research and counselling, Qualitative Inquiry 9, 6, 915-33

Schmidt, A, 2007, I know what you're doing, reflexivity and methods in refugee studies, Refugee Survey Quarterly 26, 3, 82-98

Scott, P, 1999, Black people's health: ethnic status and research issues, in A Hood, B Mayalland, S Oliver (eds) Critical issues in social research, power and prejudice, Buckingham: Open University Press

Stevenson, J, 2009, The methodological and ethical implications of 'story telling' in educational research, presented at the ESREA conference 'Wisdom and knowledge in researching and learning lives: diversity, difference and commonalities', Milan, March

Watts, J, 2008, Emotion, empathy and exit: reflections on doing ethnographic qualitative research on sensitive topics, Medical Sociology online 3, 2, 3-14

Wax, M, Shapiro, LJ, 1956, Repeated interviewing, The American Journal of Sociology 62, 2, 215-17

Young, AA, 2004, Experiences in ethnographic interviewing about race: the inside and outside of it, in M Bulmer, J Solomos (eds) Researching race and racism, London: Routledge, 187-202 